\title{
Margaret McCartney: If screening is worth doing, it's worth doing well
}

\author{
Margaret McCartney general practitioner
}

Glasgow

Atrial fibrillation is common, strokes resulting from it are often preventable, it's often diagnosed coincidentally, and some people have the condition but no diagnosis. Screening for atrial fibrillation, therefore, should get under way without delay: on the face of it, like so much in medicine, such thinking seems to make sense.

After all, we have gadgets to make the diagnosis quickly and cheaply in primary care (or anywhere, if you have a smartphone). And a range of anticoagulants don't require monitoring and are coming down in price.

This line of argument is also popular, especially with the political classes. As a result we see numerous "innovation" projects pushing screening, with few people standing in the way. NICE has proposed documenting pulse rhythm as a quality indicator in patients with conditions including hypertension and ischaemic heart disease. ${ }^{1}$ A report for the Scottish parliament's Cross Party Group on Heart Disease and Stroke recommended "case finding" for at-risk groups, including all over $65 \mathrm{~s} .^{2}$ There's a push to screen more people, through the Academic Health Science Networks (one of whose aims is "fostering opportunities for industry"), ${ }^{3}$ and pilot studies claim "lifesaving" pathways for atrial fibrillation screening in people attending pharmacies. But what might seem to make logical sense is challenged by evidence and the gaps in it.

For screening to be effective it's important to know who will benefit from it. One needs to know the denominator when working out the chances of patients being harmed or deriving benefit. The lower the prevalence of a particular condition, the higher the risk of generating false positives - and the greater the harms generated become, relative to the benefits. Yet the populations examined in the various local pilots and experiments of atrial fibrillation screening vary widely. People visiting a supermarket are different from those attending a pharmacy, who in turn are different from those who have made an appointment to see their GP.

No amount of glossy reports or gadgets is a substitute for getting the evidence right to start with
Population screening for atrial fibrillation is not recommended by the UK National Screening Committee. ${ }^{5}$ When the committee last deliberated on this in 2014 it was concerned whether screening asymptomatic people brought the same benefits as diagnosis in symptomatic groups and found a "paucity of evidence relevant to this question."

Some studies have investigated the comparative outcomes of symptomatic versus asymptomatic detection. But the results are mixed, and the studies are often poorly designed. They're not often controlled, lead time bias is rampant, and they haven't always categorised asymptomatic detection in terms of population risk. ${ }^{6}$

The news of a large controlled study of screening over $65 \mathrm{~s}$ in England is welcome ${ }^{7}$-but it should also be a reason to stop the overfinanced "innovation" pilots that can't hope to deliver the quality of evidence necessary to recommend themselves.

If screening is worth doing, it's worth doing correctly. No amount of glossy reports or gadgets is a substitute for getting the evidence right to start with.

What dismays me most is the call for action, rather than for better evidence, from groups who really should know better.

Competing interests: See www.bmj.com/about-bmj/freelance-contributors/margaretmccartney.

Provenance and peer review: Commissioned; not externally peer reviewed.

National Institute for Health and Care Excellence. New indicators to be added to the NICE indicator menu for general practice. 1 Aug 2017. https://www.nice.org.uk/Media/Default/ Standards-and-indicators/indicators-general-practice.pdf.

2 Cross-Party Group on Heart Disease and Stroke. A focus on atrial fibrillation in Scotland. 2018. https://www.bhf.org.uk/-/media/files/heart-voices/a-focus-on-atrial-fibrillation-inscotland.pdf?la=en

Academic Health Science Networks. About Academic Health Science Networks. 2017. http://www.ahsnnetwork.com/about-academic-health-science-networks/.

4 Care City. Launching our life-saving Atrial Fibrillation Pathway at EXPO2017. www.carecity.london/news/updates/426-launching-our-lifesaving-atrial-fibrillation-pathway-at-expo2017. The UK NSC recommendation on atrial fibrillation screening in adults. July 2014. https:// legacyscreening.phe.org.uk/atrialfibrillation.

6 Siontis KC, Gersh BJ, Killian JM, etal . Typical, atypical, and asymptomatic presentations of new-onset atrial fibrillation in the community: Characteristics and prognostic implications. Heart Rhythm 2016;13:1418-24. 10.1016/.jhrthm.2016.03.003 26961300 
7 Nuffield Department of Primary Care Health Sciences. Upcoming trial involving 120000 patients to investigate screening for atrial fibrillation. 16 May 2018. https://www.phc.ox. ac.uk/news/new-research-to-investigate-whether-screening-can-prevent-one-in-ten-strokes.
Published by the BMJ Publishing Group Limited. For permission to use (where not already granted under a licence) please go to http://group.bmj.com/group/rights-licensing/ permissions 